\title{
Author Correction: The Inhibitory Effect of Mesenchymal Stem Cells with rAd-NK4 on Liver Cancer
}

\author{
Chao Cai ${ }^{1} \cdot$ Lingling Hou ${ }^{1} \cdot$ Jingsi Zhang ${ }^{1}$. \\ Diandian Zhao ${ }^{1} \cdot$ Ziling Wang $^{1} \cdot$ Honggang $\mathrm{Hu}^{1}$ • \\ Jinsheng $\mathrm{He}^{1}$ - Weijun Guan ${ }^{2}$ - Yuehui $\mathrm{Ma}^{2}$
}

Published online: 11 April 2018

(C) Springer Science+Business Media, LLC, part of Springer Nature 2018

\section{Author Correction: Appl Biochem Biotechnol \\ https://doi.org/10.1007/s12010-017-2456-x}

The original version of this article unfortunately contained a mistake in the image of Figure 7. During the final submission of high-resolution figures for this manuscript's publication, the second image in Figure $7 \mathrm{~b}$ were inadvertently replaced with the first image. The second image of Figure $7 \mathrm{~b}$ in published version is therefore incorrect. The corrected version of the figure, as originally submitted and reviewed in all versions before the last, is shown below. The only change is in the panels of the second image in Figure $7 \mathrm{~b}$; the rest of the figure is identical to the published version. We apologize for this oversight and for any confusion that it has caused.
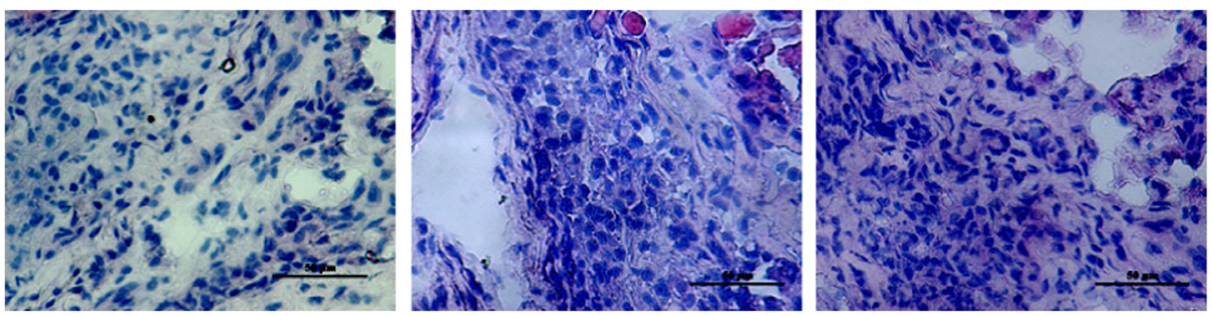

The online version of the original article can be found at https://oi.org/10.1007/s12010-017-2456-x

Lingling Hou

1lhou@bjtu.edu.cn

1 College of Life Sciences and Bioengineering, Beijing Jiaotong University, Beijing 100044, People's Republic of China

2 Institute of Animal Sciences, Chinese Academy of Agricultural Sciences (CAAS), Beijing 100193, People's Republic of China 